\section{Root Canal Penetration of a Sodium Hypochlorite Mixture Using Sonic or Ultrasonic Activation}

\author{
Marta Sáinz-Pardo ${ }^{1}$, Roberto Estevez ${ }^{1}$, Óliver Valencia de Pabloํㅜ, Giampiero \\ Rossi-Fedele ${ }^{2}$, Rafael Cisneros ${ }^{1}$
}

'Department of Endodontics, Universidad Europea de Madrid, Madrid, Spain ${ }^{2}$ The University of Adelaide, South Australia, Australia

Correspondence: A/Prof. Giampiero Rossi-Fedele, University of Adelaide, SA 5005 Australia. Tel.: +61-(0)8-831-39 Fax +61(0)83133444. e-mail giampiero. rossi-fedele@adelaide.edu.au

Key Words: root canal irrigation, ultrasonic, sonic, positive pressure, activation.
The purpose of this ex vivo study was to determine, in "open" and "closed" systems, whether the design has an influence on the penetration length of sodium hypochlorite mixed with a radiopaque contrast medium, measured in millimeters, when delivered using positive pressure (PP) and using sonic (SI) or passive ultrasonic (PUI) activation. Sixty single-rooted teeth were divided into two groups: open and closed systems $(n=30)$. Root canal shaping was performed to a working length of $17 \mathrm{~mm}$. The samples were divided into three sub-groups $(n=10)$ according to irrigant delivery and activation: $\mathrm{PP}$, and SI or PUI activation. By using radiographs, penetration length was measured, and vapor lock was assessed. For the closed group, the penetration distance means were: PP $15.715( \pm 0.898)$ $\mathrm{mm}$, SI $16.299( \pm 0.738) \mathrm{mm}$ and PUI $16.813( \pm 0.465) \mathrm{mm}$, with vapor lock occurring in $53.3 \%$ of the specimens. In the open group, penetration to $17 \mathrm{~mm}$ occurred in $97.6 \%$ of the samples, and no vapor lock occurred. Irrigant penetration and distribution evaluation using open and closed systems provide significantly different results. For closed systems, $\mathrm{PUI}$ is the most effective in delivering the irrigant to working length, followed by SI.

\section{Introduction}

Sonic and ultrasonic irrigant agitation devices have been initially suggested in root canal treatment to enhance debridement after shaping. Their differences in oscillation frequency reflect on tip movement amplitude and subsequent oscillating pattern, with the latter having higher frequencies (>20 kHz) but lower amplitudes (1). Ultrasonic irrigation without simultaneous root canal instrumentation, by aiming for the file not to bind the root canal walls, has been termed Passive Ultrasonic Irrigation (PUI) (2), although the term "Ultrasonically Activated Irrigation" has been proposed recently, as file-to-wall contact nonetheless occurs (3).

The root canal system is normally a closed-end canal, as the roots are usually embedded in the periodontal tissues and the alveolar bone (4), although certain pathways of reduced resistance towards soft tissues, such as periapical lesions, perforations or direct communication with the maxillary antrum, have been suggested (5). Further exceptions are selected endodontic surgery procedures such as periradicular surgery with a "through and through" approach, replacement surgery, and preparation for corrective surgery in teeth where the root has lost a great amount of bone support. The clinical significance of irrigants reaching the most apical part of the root canal is related to the fact that the management of teeth with apical periodontitis aims to disrupt the biofilms in this area, as surviving microorganisms are associated with treatment failure (6). Furthermore, the presence of incompletely treated pulp tissues is suggested as a potential cause of persistent pain in vital cases (7).

The effects of gas entrapment on root canal debridement have been demonstrated in vitro using "closed" and "open" system designs. These investigations found that apical vapor lock had adverse effects, and questioned the clinical relevance of conclusions derived from assays where the fluid flow through the apical foramen is not adequately restricted (8). Although several investigations have looked into the effect of activation in terms of the ability of irrigants to reach working length (WL), only recently ex vivo models have emphasized the role of closed systems, and a dichotomous approach whereby the irrigant "reaches the WL" or "does not reach the WL" has been used. Additionally, to the best of our knowledge, no investigation has directly compared irrigant penetration length per se in "open" and "closed" systems. Current techniques for evaluating irrigant penetration and distribution include direct observation of cleared teeth ex vivo (9-13) or radiographic contrast ex vivo $(9,10)$, in vivo $(2,13-5)$, as well as simulated plastic canals (16).

The purpose of this ex vivo study was to determine, in "open" and "closed" systems, whether system design has an influence on a $\mathrm{NaOCl}$-containing contrast solution penetration length measured in millimeters and vapor lock formation, when delivered using positive pressure (PP) and sonic (SI) or passive ultrasonic (PUI) activation. 


\section{Material and Methods}

Sixty single-rooted upper incisor teeth were used in this study. Teeth were kept for two $\mathrm{h}$ in $4 \% \mathrm{NaOCl}$, and any visible calculus was removed ultrasonically. The presence of a single canal was verified radiographically by taking three angulated films and by direct exploration under a dental operating microscope (OPMI Pico Dental Microscope; Carl Zeiss, Oberkochen, Germany). All experimental procedures were performed by the same operator. The patency of the root canals was obtained using a $10 \mathrm{~K}$-file (Maillefer, Ballaigues, Switzerland), and root length was standardised to $18 \mathrm{~mm}$.

The specimens were randomly allocated to 2 groups: Group 1. Closed system $(n=30)$. The root apex was covered with paste-paste adhesive (Pattex Extrem-Pro Henkel, Düsseldorf, Germany) (Fig. 1A and 1B), prepared according to the manufacturer's instructions, to achieve a fluid tight seal. Group 2. Open system $(n=30)$. The apical foramen was left uncovered (Figs. 1C and 1D).

Root canal shaping was performed to a working length (WL) of $17 \mathrm{~mm}$, using Profile rotary files (Maillefer) of up to 30 size 0.06 taper. During this instrumentation, all samples received $1.5 \mathrm{~mL}$ of $4.25 \% \mathrm{NaOCl}$, which was delivered between each instrument by using a 30G Max-i-Probe (Dentsply-Rinn, Elgin, IL, USA).

Following instrumentation, a coronal reservoir of wax (Hygienic; Colténe/Whaledent, Altsttäten, Switzerland) was made to resemble the pulp chamber and retain the irrigant solution (Figs. 1B and 1D). Subsequently, samples were randomly allocated to 3 sub-groups according to the irrigation delivery system: Subgroups $1 \mathrm{~A}$ and $2 \mathrm{~A}$ $(n=10$ each). Using a 30G Max-i-Probe (Dentsply-Rinn) at WL-2 mm. Subgroups 1B and 2B ( $n=10$ each). Using the
Endoactivator (Advanced Endodontics, Santa Barbara, CA, USA) with a 25/.04 tip, set at 10000 cycles per minute per $30 \mathrm{~s}$, placed at WL-2 mm. Subgroups $1 \mathrm{C}$ and $2 \mathrm{C}(\mathrm{n}=10$ each). Using an untapered Irri-S tip size 25 (VDW GmbH, Munich, Germany) mounted on an Ultra ultrasonic unit (VDW), set
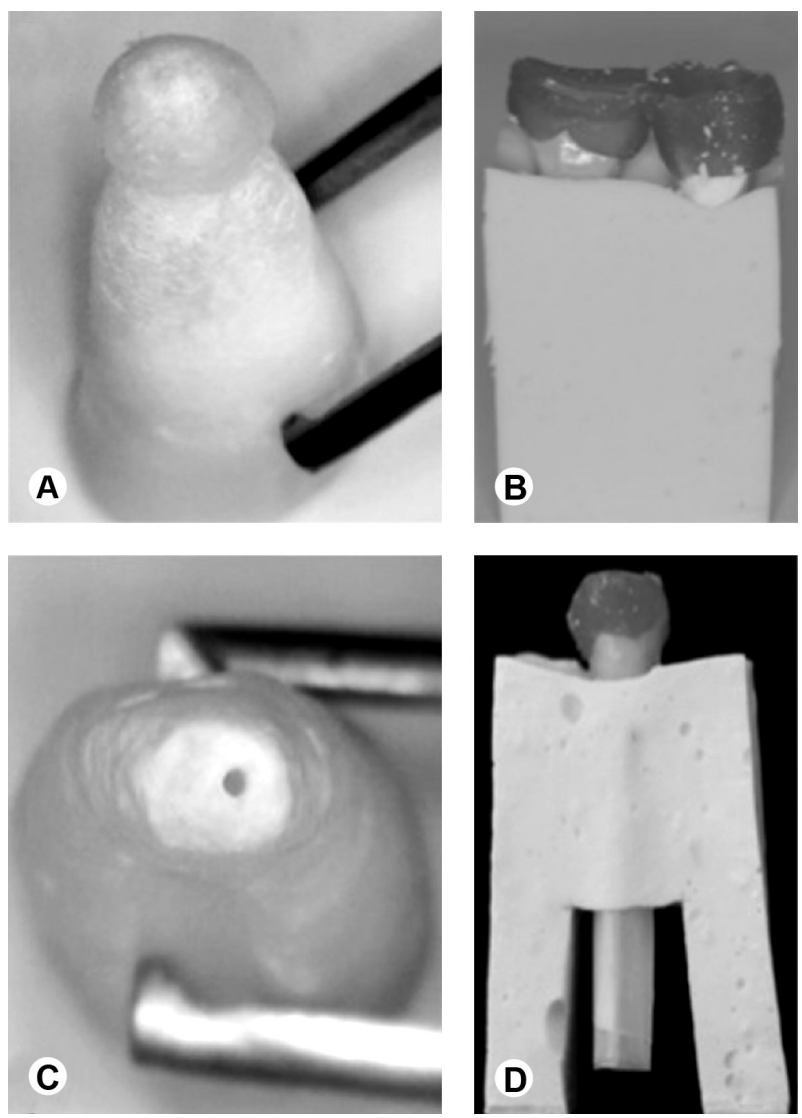

Figure 1. Closed system (A). Closed system mounted in alginate (B). Open system (C). Open system mounted in alginate (D).
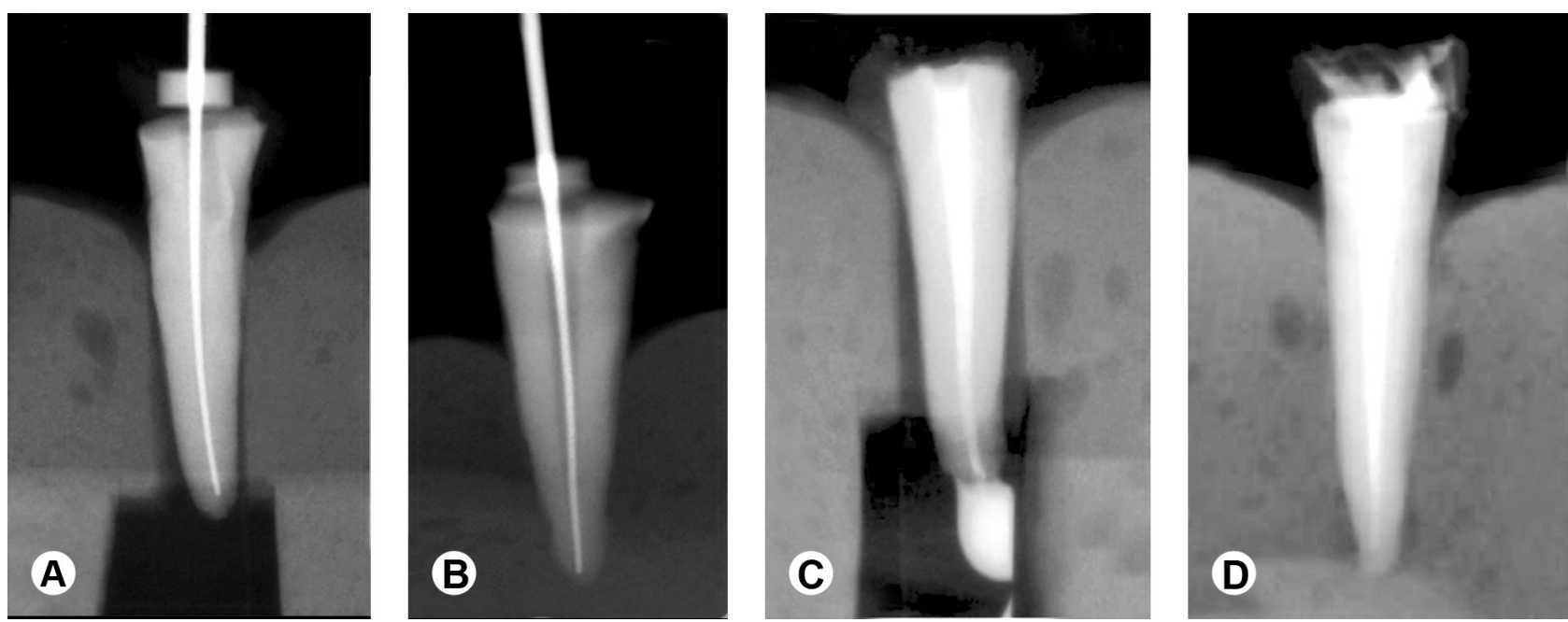

Figure 2. Working length confirmation radiographs (A,B). Open system specimen post-irrigation radiograph showing irrigant extrusion (C). Closed system specimen post-irrigation radiographic image showing irrigant penetration (D). 
at power 25 (Irri-mode) for $30 \mathrm{~s}$, placed at WL-2 mm.

The final irrigation sequence was as follows: $1.5 \mathrm{~mL}$ of $4.25 \% \mathrm{NaOCl}$ followed by $1.5 \mathrm{~mL}$ of $17 \%$ EDTA, and a final rinse with $4.25 \% \mathrm{NaOCl}$ at $2 \mathrm{~mm}$ from the $\mathrm{WL}$, using the Max-i-Probe.

The canals were then dried using paper points, and the teeth mounted in alginate (Zhermack, Badia; Polesine, Italy) blocks with standard dimensions (Fig. 1B). For the open system group, the external surface of the root was protected with adhesive tape (Fig 1D).

\section{Contrast Solution Preparation and Irrigant Penetration Evaluation}

$A$ radiograph in bucco-lingual direction with the master apical file (MAF), a size $30 \mathrm{~K}$-Flexofile (DentsplyMaillefer) (Figs. 2A and 2B), was exposed to confirm that the MAF reaches the desired WL (X Mind $40 \mathrm{~cm}$ Satelec, Madrid, Spain).

The contrast solution was prepared by mixing $40 \%$ lomeron $300^{\circledast}$ (Bracco, Milan, Italy) and 60\% 4.25\% NaOCl. Pilot studies carried out prior to the main investigation showed a better visualization of the contrast with this ratio.

One milliliter of the contrast solution was delivered at WL-2, using a Max-i-Probe $30 \mathrm{G}$ syringe, and left in situ for $30 \mathrm{~s}$. For subgroups with sonic and ultrasonic activation, the solution was then agitated for $30 \mathrm{~s}$, with the tips placed at WL-2 $\mathrm{mm}$.

A second radiograph, following irrigation with the contrast medium, was exposed (Figs. 2C and 2D), with consistent angulation, direction and distance of x-ray beams, when compared with the MAF image. The radiographic apparatus settings were maintained unchanged during the study.

\section{Evaluation Criteria}

To measure the depth of contrast penetration, the software Photoshop Extended CS5.1. version (Adobe Systems Incorporated, San Jose, CA, USA) was used to

Table 1. Irrigant penetration depth and vapor lock percentage of the closed systems subgroups

\begin{tabular}{lccc}
\hline Subgroup & $\mathrm{n}$ & $\begin{array}{c}\text { Mean solution penetration } \\
\text { depth }(\mathrm{mm}) \pm \mathrm{SD}\end{array}$ & $\begin{array}{c}\text { Vapor } \\
\text { lock }(\%)\end{array}$ \\
\hline Positive Pressure & 10 & $15.715 \pm 0.898^{\mathrm{a}}$ & 70 \\
$\begin{array}{l}\text { Sonic activation } \\
\begin{array}{l}\text { Passive ultrasonic } \\
\text { activation }\end{array}\end{array}$ & 10 & $16.299 \pm 0.738$ & 60 \\
\hline
\end{tabular}

Groups identified by different superscript letters indicate significant statistical difference in regards to irrigant penetration $(p=0.020)$. No significant differences were found in regards to vapor lock percentage $(\mathrm{p}=0.169)$. SD: standard deviation. process radiographic images. The ruler tool was selected to obtain a customized scale of $17 \mathrm{~mm}$ by calibrating the length of the MAF in the first radiograph of each sample. Then, based on this scale, the penetration length was measured in $\mathrm{mm}$ in the matching post-irrigation images.

Finally, post-irrigation radiographs were assessed for vapor lock. The samples were scored by a trained evaluator who was blinded for subgroup assignments pertaining to each sample, but not to the type of system, because of the obvious differences in radiographic image.

\section{Statistical Analysis}

The $\chi^{2}$ test was used to analyze qualitative variables. For quantitative variables, the Kruskal-Wallis and MannWhitney U-test were used. The level of significance was set at $p<0.05$. Statistical analysis was performed using SPSS 15.0 for Windows (SPSS Inc., Chicago, IL, USA).

\section{Results}

\section{Irrigants Penetration Depth}

In the open systems, $17 \mathrm{~mm}$ (full WL) was reached in $97.6 \%$ of the samples, the only exception being a single sonically activated specimen, in which a length of $16.9 \mathrm{~mm}$ was reached. No statistically significant differences were found between the subgroups.

In closed systems, $17 \mathrm{~mm}$ was reached in $43.3 \%$ of the samples, with statistically significant differences when compared to the open systems $(p=0.001)$. Statistically significant differences between the closed system subgroups were shown $(p=0.020)$ only between PP and PUI (Table 1).

\section{Vapor Lock Analysis}

In the open systems, no sample presented with vapor lock. In the closed systems, $53.3 \%$ of the roots presented with vapor lock overall. No statistically significant differences were found between the subgroups $(p=0.169)$ (Table 1).

\section{Discussion}

$\mathrm{NaOCl}$ activation with sonic and ultrasonic means has previously been shown to be more efficient at irrigant replacement at the apical third, by breaking the vapor lock and moving the solutions apically and laterally in closed systems ex vivo (9). The present results are in concordance with investigations using closed systems when comparing similar delivery and agitation methods $(2,4,10)$. An in vivo investigation, using a radiopaque irrigant, showed that PUI is more effective than a conventional syringe in delivering this solution to $\mathrm{WL}$, with mean distances from the WL of $0.21 \mathrm{~mm}$ and $1.51 \mathrm{~mm}$ respectively (2); similarly, our investigation suggested means of 0.187 and 1.287 
$\mathrm{mm}$ for these groups. The penetration of $\mathrm{NaOCl}$ in vitro has previously only been looked at as a "binary variable". An investigation using cleared teeth showed that positive pressure is extremely unsuccesful in delivering irrigants to the WL, whilst in $40 \%$ of those activated with $\mathrm{SI}$ and $65 \%$ of those activated with PUI, the irrigant reached WL (4). When comparing different canals prepared to tapers 0.04 or 0.08 using a radiographic contrast, $66.7-73.3 \%$ of the samples activated with PUI and $20-47.7 \%$ of the samples activated with SI reached WL (10). In our study, the same apical preparation size was aimed for, and a 0.06 taper was achieved, with the contrast irrigant reaching the full WL in $43.3 \%$ of the closed systems samples.

Our results confirm the differences between closed and open systems in regards to vapor lock formation in vivo $(2,13-5)$ and in vitro (8). A recent investigation, using transparent resin blocks and a computational approach, found vapor lock formation in $48 \%$ of the cases (11), similar to our $53.3 \%$ value. It is worth mentioning that apart from vapor lock, differences in irrigant flow between open and closed experimental models may explain the dissimilarities in the observed irrigant penetration (11).

The use of non-cleared teeth aims to prevent chemical modifications of the dentine, in order to allow a larger degree of gas bubble formation because of interaction with $\mathrm{NaOCl}$. In the absence of organic matter, gas bubbles are not readily formed because of its degradation with $\mathrm{NaOCl}$.

$\checkmark$ Therefore, simulated plastic canals, and possibly cleared teeth, mostly take into account the air originally entrapped by the solution. A similar problem occurs if radiopaque mixtures do not contain $\mathrm{NaOCl}$. In vitro simulated plastic canal models have previously been criticized, as the samples may act differently to dentine due to the dentin's porous nature, the presence of complicated morphology (17), and because of the hydrophobic surface of the plastic (5). Furthermore, in vivo investigations have used radiopaque solutions to evaluate irrigation dynamics $(2,13-5)$, with the detection of radiopaque solutions in vitro suggested to be more predictable because of the lack of anatomic interference (13).

It is worth mentioning that several physical characteristics of the mixtures which are used to visualize root canal penetration are dissimilar to those of commonly used irrigants, and this may have an influence on their rheology (18). Therefore, the flow of unmixed $\mathrm{NaOCl}$ can be different in clinical reality when compared to experimental models. Further understanding of the role of surface tension and viscosity of root canal irrigants, and their relevance with regards to flow when in contact with a moist surface such as dentine, is required (18).

Several procedures have been advocated to improve irrigation dynamics in regards to vapor lock and apical penetration. Apical patency is associated with an improvement in apical delivery and an overall reduction of gas bubble presence in vivo (13-5). Basic research investigations suggest that the use of apical negative pressure predictably irrigates the canals to the full WL $(4,12)$. Root canal preparation apical size influences taper lock size (11), whilst in curved canals, preparation taper affects the ability of sonic irrigation to deliver $\mathrm{NaOCl}$ to the full length, whilst it has no influence for PUI (10). Finally the insertion of the needle tip up to WL, or by increasing the irrigant flow rate, allows the established vapor lock to be reduced in vitro (11). From these results, it may be concluded that overall, ex vivo irrigant penetration and distribution evaluation using open and closed systems gives significantly different results. For closed systems, agitation PUI is most effective in delivering the irrigant to $\mathrm{WL}$, followed by SI. PP delivery was the least efficient irrigation method.

\section{Resumo}

0 objetivo deste estudo in vivo foi determinar, para os sistemas "abertos" e "fechados", se o design tem influência na penetração, em milímetros, do hipoclorito de sódio misturado com um meio radiopaco quando empregado na ativação com pressão positiva (PP) e ativação sônica (SI) ou ultrassônica passiva (PUI). Sessenta dentes unirradiculares foram divididos em dois grupos: sistema aberto e sistema fechado $(n=30)$. Os canais radiculares foram trabalhados até um comprimento de trabalho de $17 \mathrm{~mm}$. Os grupos foram subdivididos em três subgrupos $(n=10)$ de acordo com a solução irrigadora e a ativação: PP, e ativação SI ou PUI. Usando radiografias, a distância de penetração foi medida e avaliado o vapor contido. Para o grupo fechado, as distâncias médias de penetração foram PP 15,715 ( $\pm 0,898) \mathrm{mm}$, SI 16,299 $( \pm 0,738) \mathrm{mm}$ e PUI 16,813 $( \pm 0,465) \mathrm{mm}$ e houve vapor contido em $53,3 \%$ das amostras. No grupo aberto, houve penetração de $17 \mathrm{~mm}$ em 97.6\% das amostras, sem contenção de vapor. A penetração do irrigante e avaliação da distribuição usando sistemas aberto e fechado produziram resultados significativamente diferentes. Para os sistemas fechados, PUI é mais eficaz para levar o irrigante até preencher o comprimento de trabalho, seguido por SI.

\section{References}

1. Gu LS, Kim JR, Ling J, Choi KK, Pashley DH, Tay FR. Review of contemporary irrigant agitation techniques and devices. J Endod 2009;35:791-804.

2. Munoz HR, Camacho-Cuadra K. In vivo efficacy of three different endodontic irrigation systems for irrigant delivery to working length of mesial canals of mandibular molars. J Endod 2012;38:445-448.

3. Boutsioukis $C$, Veerhaagen $B$, Walmsley $A D$, Versluis $M$, van der Sluis LW. Measurement and visualization of file-to-wall contact during ultrasonically activated irrigation in simulated canals. Int Endod J 2013;46:1046-1055.

4. de Gregorio C, Estevez R, Cisneros R, Paranjpe A, Cohenca N. Efficacy of different irrigation and activation systems on the penetration of sodium hypochlorite into simulated lateral canals and up to working length: an in vitro study. J Endod 2010;36:1216-1221.

5. Boutsioukis C, Psimma Z, van der Sluis LWM. Factors affecting irrigant extrusion during root canal irrigation: a systematic review. Int Endod 2013;46:599-618.

6. Nair PNR, Sjöegren U, Krey G, Kahnberg KH, Sundqvist G. Intraradicular bacteria and fungi, in root-filled, asymptomatic human teeth with therapy-resistant periapical lesions: a long term light and electron microscopic study. J Endod 1990;16:580-588. 
7. Nixdorf DR, Moana-Filho EJ, Law AS, McGuire LA, Hodge JS, John MT. Frequency of persistent tooth pain after root canal therapy: a systematic review and meta-analysis. J Endod 2010;36:224-30.

8. Tay FR, Gu L, Schoeffel GJ, Wimmer C, Susin L, Zhang K, et al.. Effect of vapor lock on root canal debridement by using a side-vented needle for positive-pressure irrigant delivery. J Endod 2010;36:745-750.

9. de Gregorio C, Estevez R, Cisneros R, Heilborn C, Cohenca N. Effect of EDTA, sonic, and ultrasonic activation on the penetration of sodium hypochlorite into simulated lateral canals: an in vitro study. J Endod 2009;35:891-895.

10. Merino A, Estevez R, Gregorio C, Cohenca N. The effect of different taper preparations on the ability of sonic and passive ultrasonic irrigation to reach the working length in curved canals. Int Endod J 2013:46:427-433.

11. Boutsioukis $C$, Kastrinakis $E$, Lambrianidis $T$, Veerhagen $B$, Verluis $M$, van der Sluis LWM. Formation and removal of apical vapor lock during syringe irrigation: a combined experimental and computational fluid dynamics approach. Int Endod J 2014;47:191-201.

12. de Gregorio C, Paranjpe A, Garcia A, Navarrete N, Estevez R, Esplugues EO, et al.. Efficacy of irrigation systems on penetration of sodium hypochlorite to working length and to simulated uninstrumented areas in oval shaped root canals. Int Endod J 2012;45:475-481.

13. Vera J, Arias A, Romero M. Effect of maintaining apical patency on irrigant penetration into the apical third of root canals when using passive ultrasonic irrigation: An in vivo study. J Endod 2011;37:1276-
1278.

14. Vera J, Arias A, Romero M. Dynamic movement of intracanal gas bubbles during cleaning and shaping procedures: the effect of maintaining apical patency on their presence in the middle and cervical thirds of human root canals - An in vivo study. J Endod 2012;38:200203.

15. Vera J, Hernández EM, Romero $M$, Arias $A$, van der Sluis LW. Effect of maintaining apical patency on irrigant penetration into the apical two millimetres of large root canals: an in vivo study. J Endod 2012;38:1340-1343.

16. Psimma Z, Boutsioukis C, Vasiliadis L, Kastrinakis E. A new method for real-time quantification of irrigant extrusion during root canal irrigation ex vivo. Int Endod J 2013;46:619-631.

17. van der Sluis LWM, Wu M-K, Wesselink PR. The efficacy of ultrasonic irrigation to remove artificially placed dentine debris from human root canals prepared using instruments of varying taper. Int Endod J 2005;38:764-768.

18. Rossi-Fedele G, Prichard JW, Steier L, de Figueiredo JAP. The effect of surface tension on the clinical performance of sodium hypochlorite in endodontics. Int Endod J 2013;46:492-8.

Received June 3, 2014 Accepted October 20, 2014 